\title{
The Perfect Match: Simultaneous Strawberry Pollination and Bio-Sampling of the Plant Pathogenic Bacterium Erwinia pyrifoliae by Honey Bees Apis mellifera
}

\author{
J. J. M. van der Steen ${ }^{1}$, M. Bergsma-Vlami ${ }^{2}$ \& M. Wenneker ${ }^{3}$ \\ ${ }^{1}$ Wageningen University \& Research. Netherlands \\ ${ }^{2}$ Dutch National Plant Protection Organisation (NPPO-NL); Netherlands Food and Consumers Product Safety \\ Authority, Netherlands \\ ${ }^{3}$ Wageningen Plant Research, Applied Bulb, Trees and Fruit Research, Wageningen University \& Research, \\ Netherlands
}

Correspondence: J. J. M. van der Steen, Wageningen University \& Research, P.O. Box 16, 6700 AA Wageningen, Netherlands. Tel 313-1748-1331. E-mail: sjef.vandersteen@wur.nl

\author{
Received: July 26, 2017 Accepted: August 23, 2017 Online Published: October 24, 2017 \\ doi:10.5539/sar.v7n1p25 URL: https://doi.org/10.5539/sar.v7n1p25
}

\begin{abstract}
In this study we show that honey bee colonies placed in a greenhouse for pollination of strawberry can simultaneously be used to indicate the presence of the plant pathogenic bacterium Erwinia pyrifoliae. This was demonstrated by using two methods of qualitative sacrificial and non-sacrificial bio sampling of the honey bee colony. A novel method for non-sacrificial subsampling, named the Beehold device, was applied. Applying the Beehold device did not disturb or affect negatively the honey bee colony. The study demonstrated that the integration of pollination service and bio-sampling functioned. In the sacrificially derived honey bee subsamples, E. pyrifoliae was detected prior to any visible infection in the plant; however, E. pyrifoliae was detected via non-sacrificial sampling at the same time as plant infection was first observed. The Beehold device is a practical tool for monitoring plant pathogens via forager bees during flowering until fruit onset, but is not as sensitive as directly sampling honey bees.
\end{abstract}

Keywords: Beehold tube, bio sampling, Erwinia pyrifoliae, honey bee, non-sacrificial subsampling, sacrificial subsampling

\section{Introduction}

Honey bees (Apis mellifera) are widely employed for pollination of horticultural crops. Pollination by the honey bee occurs when workers inadvertently transfer pollen from male flower anthers to receptive female flower stigmas during nectar and pollen foraging. Foraging behaviour is affected by the colony and brood nest - pollen and nectar foragers of colonies with relatively large brood nests collect larger pollen loads and perform longer forager trips than those from smaller colonies (Eckert et al., 1994). Although pollen foragers are insensitive for the quality of the pollen they collect, decrease in quantity and quality of pollen results in an increase of the proportion of pollen foragers without increasing the overall foraging rate and pollen load weight (Pernal \& Currie, 2001). During foraging, pollen and non-floral particles such as plant pathogenic bacteria and atmospheric deposited particles can adhere to the branched hairs of honey bees (Wadl et al., 2009). Honey bees groom themselves during foraging, and are further groomed by their in-hive sisters (Hodges, 1974; Bozic \& Valentincic, 1995). Despite grooming, both pollen and non-floral particles passively remain on the bee's exterior (Lukoschus, 1957). Free \& Williams (1972) estimated an average number of 4000 - 13000 pollen grains remain as a passive load on the honey bee. Paalhaar et al. (2008) demonstrated that honey bees that never left the colony have pollen in their hair, and that relatively small grains are dominant. Therefore, through in-hive pollen exchange, both in-hive and forager bees can carry a passive load (Degrandi-Hoffman et al., 1984, 1986). This makes the honey bee an active bio sampler of the environment, as well as a disseminator of plant pathogenic and non-pathogenic micro-organisms. For the latter, honeybee colonies are used as vectors to disseminate antagonistic micro-organisms directly into the flowers to prevent or inhibit pathogenic organisms growth. (Kovach et al., 2000; Kevan et al., 2008). Dissemination of plant pathogenic bacteria does not always result in disease. 
Wounding is essential for entry by many plant pathogens. Infested or infected seed or other plant parts can be sources of bacterial inoculum. Once infection occurs, bacteria exudates are released through cracks or wounds in the infected area, or through natural openings such as stomata. Such bacteria are then likely to stick to the legs and bodies of insects, such as honey bees, flies, aphids and ants that land on the plant and come in contact with the bacterial exudates. Many of these insects are actually attracted by the sugars contained in the bacterial exudate and feed on it, thereby further smearing their body and mouthparts with the bacteria-containing exudate. When such bacteria-smeared insects move to other parts of the plant or to other susceptible host plants, they carry numerous bacteria on their body. As a result, the honey bee's feature of unintentional collection of non-floral particles makes each foraging honey bee an in-flower bio sampling honey bee. Subsampling of the honey bee colony for particles, including micro-organisms, can be done sacrificially or non-sacrificially. Sacrificial subsampling implies killing bees for analysis. Considering the honey bee's performance, sacrificial subsampling has its practical limits regarding frequency and sample size. In contrast, non-sacrificial subsampling does not occur at the expense of the honey bee colony. The trick of non-sacrificial honey bee colony subsampling is to remove particles from the bee's exterior without taking bees. The number of bees for non-sacrificial sampling is unlimited, with one single bee potentially sampled multiple times. Combining pollination service and bio sampling of plant pathogenic bacteria by the honey bee colony is therefore a logical match. This has been demonstrated during Erwinia amylovora studies. E. amylovora is the causative agent of fire blight, a disease of rosaceous plants that occurs in many countries around the world (Bonn \& Zwet, 2000). In Italy, Austria and Switzerland, bees have been successfully used to detect Erwinia amylovora in flowering appleand pear orchards. (Porrini et al., 2002; Halbwirth et al., 2014). Very few bacterial diseases are known from strawberry. In 1962, Xanthomonas fragariae, the causal agent of bacterial angular leaf spot of strawberry in Minnesota, USA, was reported (Kennedy \& King, 1962). Atanasova et al., 2005 described finding E. amylovora on infected plants of Fragaria ananassa and Fragaria moshata. Recently, Erwinia pyrifoliae was described as the causative agent of a bacterial disease affecting production of strawberry under greenhouse cultivation conditions. Symptoms included brown petals, green young fruits turning brown, malformed fruits and bacterium slime on the surface of the young fruits (Wenneker \& Bergsma-Vlami, 2015).

The aim of this study was to investigate if E. pyrifoliae in flowering strawberry greenhouse cultivation can be detected via qualitative sacrificial and non-sacrificial subsampling of honey bees.

\section{Materials \& Methods}

\subsection{Study Site, Honey Bee Colonies and Study Period}

The study was conducted between March - April 2015 in a four hectare greenhouse in Made (Province Noord-Brabant, The Netherlands) that was planted with strawberry (Fragaria x ananassa, cultivar Elsanta). Honey bee colonies were obtained from the beekeeping operation Ecopol Geffen (Province Noord-Brabant, The Netherlands). The colonies were relatively small and covered 5 to 6 simplex frames $(3.5 \times 2 \mathrm{dm})$, which is approximately $6000-8000$ worker bees. Each colony had two to three frames with brood in all stages of development (Delaplane et al., 2013). To ensure sufficient pollination in the greenhouse, six honey bee colonies were replaced on April 3 with six new colonies from the Ecopol operation.

\subsection{Non-Sacrificial Subsampling with the Beehold Device}

For non-sacrificial subsampling, a novel method using the Beehold device was applied. The Beehold device, schematically presented in Figure 1, is a novel non-sacrificial subsampler of honey bees entering the hive. The method takes advantage of honey bee landing behaviour wherein hive-entering bees approach the hive entrance by landing on the flight board or outer front board to walk toward the entrance. This tube via which the bees enter the hive is the Beehold tube. Hive-leaving bees exit the hive via a walk on the bottom board or via the inside front wall to find their way out via an opening in the front board of the hive. The Beehold tube protrudes from the inner front wall into the hive to prevent hive-leaving bees to exit the hive via the Beehold tube. To prevent hive-entering bees to enter via the out-tube, the out-tube protrudes the flight board. The Beehold device consists of a foam strip that seals off the hive, therefore leaving two openings - one for the in-tube (Beehold tube) and one for the out-tube. The Beehold tube, the sampling part of the Beehold device, $11 \mathrm{~cm}$ long and with an inner diameter of $1.9 \mathrm{~cm}$, is internally covered by a thin transparent PVC foliar holding a sticky polyethylene (PEG) layer, covered with plastic gauze to stabilize the PEG's position on the PVC layer. The moderate sticky PEG layer allows particles attached to the hive-entering bee's hair and feet to adhere to it. The stickiness of the PEG depends on the ambient temperature. For this study, a mixture of one part PEG1000 and one part PEG1500 (v/v) was applied. PEG is non-toxic to bees and can be applied safely for study objectives (Crailsheim, 1985). Preliminary studies showed that $2-4 \%$ of particles on the bee's body adhere to the PEG layer in the Beehold 
tube. Figure 2 shows the Beehold tube with its translocation cover, the $50 \mathrm{ml}$ Blue cap tube; Figure 3 shows the Beehold device the flight entrance, Figure 4 shows a detail of the out-tube and Beehold tube (in-tube) and Figure 5 shows hive-entering bees via the Beehold tube.

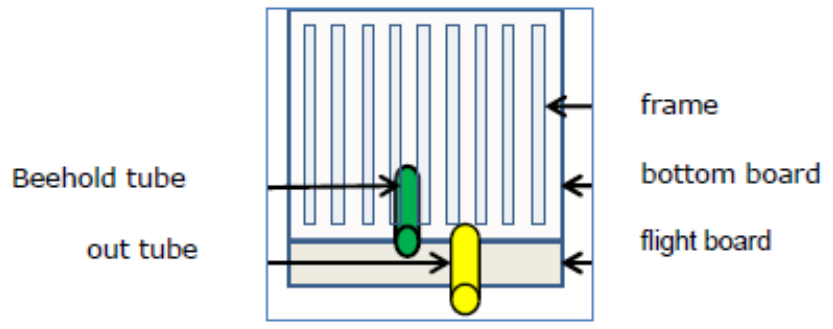

Figure 1. Top-down schematic drawing of the Beehold device and the position of the Beehold tube. Incoming bees enter the hive via the Beehold tube and are non-sacrificially subsampled by passing this tube. Bees leave the hive via the out tube

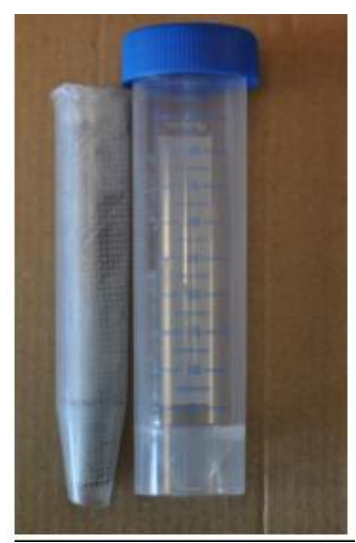

Figure 2. Beehold tube with $50 \mathrm{ml}$ Blue cap

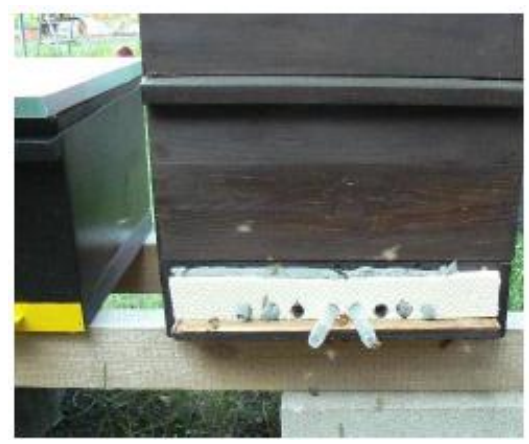

Figure 3. Beehold device in flight entrance

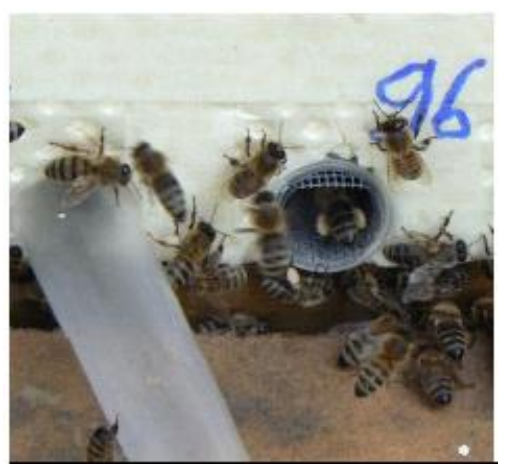

Figure 4. detail in- out tube (Beehold tube) 


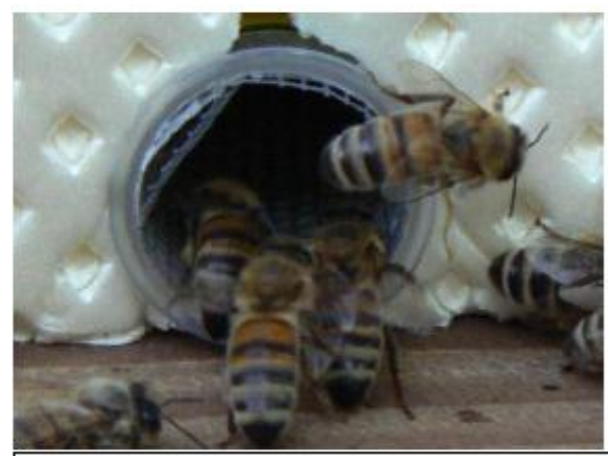

Figure 5. detail hive-entering bees via Beehold

\subsection{Pre-sampling of the Honey bee Colony at the Apiary}

On March 10, prior to the translocation of the colonies from the apiary to the greenhouse, 30 hive-entering bees were taken from one honey bee colony and tested for the presence of $E$. pyrifoliae. Beebread was not checked for E. pyrifoliae as this stored pollen is consumed by young nurse bees and therefore unlikely to circulate in the bee hive. Similarly, replacement colonies were not sampled and checked for E. pyrifoliae prior to translocation into the greenhouse.

\subsection{Subsampling of the Colonies in the Greenhouse}

On March 14, at the start of the strawberry bloom, six honey bee colonies were placed in the greenhouse for pollination. After translocation, the first and last colony in the line of the hives in the greenhouse were allocated for both sacrificial and non-sacrificial subsampling. The same was done with the second cohort of honey bee colonies. The two indicated colonies of the first cohort of colonies were subsampled from March 18 until April 1. Subsamples taken on April 8 and 15 were from the second cohort of colonies.

\subsection{Non-sacrificial Subsampling of the Honey bee Colony with the Beehold Tube}

On March 16, the Beehold device was placed in the entrance of the two colonies. From March 18, the start of the blooming, until April 15, the end of blooming the Beehold tubes were replaced weekly by new ones in the morning prior or at the start of the colony's activity. The exposure period of the hive-entering bees to the Beehold tube is the period hive-entering bees pass the Beehold tube. Because of the replacement prior to the colony's activity, the exposure period of each Beehold tube ends the day prior to the sampling day. After removal, the Beehold tubes were directly placed in a sterile $50 \mathrm{ml}$ Greiner blue cap tube, transported to the laboratory within two hours of collection. The "Protocol Beehold tube", which describes the step-by-step Beehold tube method, from preparation to analysis, can be obtained from the corresponding author.

\subsection{Sacrificial Subsampling of the Honey bee Colony}

Sacrificial subsampling was performed weekly by taking 30 bees randomly via an opening in the cover board from the top of the frames. Immediately after sampling, the bees were placed in a $50 \mathrm{ml}$ Greiner blue cap tube filled with $20 \mathrm{ml}$ phosphate saline buffer (PBS $10 \mathrm{mM}, \mathrm{pH}$ 7.2) and transported to the laboratory within two hours. Bees were collected from the top of the colony because it was assumed that pollen and particles, including micro-organisms, can be found on all bees within a hive due to physical in-hive exchange among bees; sampling above the brood nest is less invasive.

\subsection{Preparation of the Samples for Functionality Checks of the Beehold Tube and Detection of E. pyrifoliae}

In the bee laboratory, two - three droplets of Tween 80 were added to the sacrificial subsample to facilitate removal of particles from the bee hairs. Subsequently, the samples were mechanically shaken with a Vortex device for at least two minutes to suspend particles from the bee's exterior into the buffer. Next, an aliquot of $500 \mu \mathrm{l}$ buffer was pipetted in a $1.5 \mathrm{ml}$ Eppendorfer tube for pollen determination. An aliquot of $12 \mathrm{ml}$ was also pipetted into a sterile $12 \mathrm{ml}$ sealable tube and transported immediately to the microbiology laboratory. From the non-sacrificially derived Beehold tubes, the PVC layer with the PEG and gauze was removed from the Beehold tube and inserted in the Greiner $50 \mathrm{ml}$ blue cap tube in which the Beehold tube was transported. In this tube, 1.5 $\mathrm{ml}$ phosphate saline buffer was pipetted, along with one droplet of Tween 80 . To dissolve the PEG into the buffer, the blue cap tubes were horizontally placed in a rotator and agitated for at least 15 minutes at room temperature. An aliquot of $500 \mu \mathrm{l}$ of the PEG/phosphate buffer mixture was taken for pollen identification. The remainder of 
the PEG/phosphate buffer mixture was then pipetted into $12 \mathrm{ml}$ sterile tubes and transported immediately to the microbiology laboratory.

\subsection{Pollen Determination \& Functionality of the Beehold Tube}

Presence of pollen demonstrated on the Beehold tube's PEG layer demonstrated its functionality. The botanic origin of the pollen reveals where foragers visit. The $1.5 \mathrm{ml}$ Eppendorfer tubes with $500 \mu \mathrm{l}$ rinsing fluid of sacrificially-sampled honey bees and the $1.5 \mathrm{ml}$ Eppendorfer tubes with the $500 \mu 1$ mixture of PEG/phosphate buffer, were centrifuged for 10 minutes at $14000 \mathrm{rpm}$ to concentrate pollen. After centrifuging, the aliquot was poured off and the remaining pellet was re-suspended in the remaining approximately $40 \mu 1$ supernatant. Next, $10 \mu 1$ of the supernatant was pipetted on a microscope slide, dried at $70^{\circ} \mathrm{C}$ on a temperature controlled heater, covered with fuchsine stained gelatin/glycerine (Kaiser), sealed with a microscope cover glass and stored at room temperature until microscopic determination.

\subsection{Detection of Erwinia Pyrifoliae}

Recovery and population size of E. pyrifoliae on the honey bee body were determined by diluting a $20 \mu \mathrm{l}$ aliquot of extract on Yeast Peptone Glucose (YPG) agar medium plates.. Plates were incubated for 2 to 3 days at $28^{\circ} \mathrm{C}$ so that they could be inspected for bacterial colonies with morphology similar to E. pyrifoliae colonies at $96 \mathrm{~h}$. Positive and negative controls were included. Pure cultures of presumptive E. pyrifoliae isolates were identified using molecular testing (Wensing et al. 2011). Limit of detection (LOD) of E. pyrifoliae was set at 100 cells per reaction.

\section{Results}

\subsection{Foraging Activity}

Observations showed a normal foraging pattern in the crop, with fluctuations in the foraging population.

\subsection{Beehold Tube Functionality and Pre Sampling}

The hive-entering bees, sampled sacrificially prior to translocation from the apiary to the greenhouse, did not carry strawberry pollen, demonstrating the bees did not forage on strawberry prior to placement in the greenhouse. The colonies arrived in the greenhouse on March 16 and were first sampled on March 18. The March 18 samples did not contain strawberry pollen, showing that bees had not yet started to forage on the strawberry flowers in the greenhouse. A week later, the in-hive bees taken from the top bars did not contain strawberry pollen; however, the Beehold tubes did. This demonstrated foraging activity on the strawberry flowers. From April 1 onwards, all samples contained only strawberry pollen, showing the bees foraged exclusively on strawberry. Both mature and dry state of Fragaria $x$ ananassa pollen was present, which is not abnormal in strawberry pollen (Dafni et al., 2012). Strawberry pollen in the Beehold tubes demonstrated hive-entering bees passed the Beehold tube.

\subsection{Erwinia Pyrifoliae on Sacrificial Subsampled In-Hive Honey Bees}

On March 25, eleven days after introduction, and on April 1, in-hive bees of one of the two sampled colonies carried E. pyrifoliae. Again in both the April 8 and April 15 samples, the sampled replacement honey bee colonies also contained E. pyrifoliae.

\subsection{Erwinia Pyrifoliae in the Beehold Tube}

From April 1 until the end of subsampling on April 15, the Beehold tube placed in front of the colony in which $E$. pyrifoliae was identified by sacrificial subsampling on March 25 also contained E. pyrifoliae.

\section{Discussion and Conclusion}

\subsection{Foraging Activity in the Greenhouse, Bio Sampling and Colony Subsampling}

The four hectares foraging greenhouse area is a limited foraging area for honey bees compared to the 2800 hectares potential foraging area of a honey bee colony in the field. Therefore, foraging activity was lower compared to the activity in the field with optimal weather conditions. To what extent the in-greenhouse foraging activity was lower compared to the in-field activity has not been recorded nor were reliable references available. Our study demonstrated that honey bees foraged on the flowering strawberry within a greenhouse environment, and brought back pollen and viable E. pyrifoliae bacteria to the hive. As the sacrificially derived subsamples were pooled samples of 30 bees, it is unknown whether all bees in the sample carried E. pyrifoliae. Non-sacrificial subsampling with the Beehold tube is per definition qualitative, and will at most give a mean quantitative indication in case all hive-entering bees are counted. This was taken into account in the study set-up, aiming for a qualitative detection of the bacterium and not a quantitative detection and precise moment of influx 
of the bacterium. For the latter, with the applied sampling frequency, it is not possible to estimate the exact timing of the first influx of E. pyrifoliae. The in-hive physical exchange of particles on the bee's exterior among the bees in a colony occurs within days (Nixon \& Ribbands, 1952). Furthermore, it is unlikely that all $E$. pyrifoliae bacteria brought in by the bees will be evenly distributed among bees in the colony. This likely depends on the number of bacteria to be distributed and the size of the colony; low numbers of bacteria brought in by the foragers in a big colony will likely result in heterogeneous distribution of bacteria.

\subsection{Beehold Tube's Functionality and Pre Sampling}

The identification of strawberry pollen (Figure 6) and the detection E. pyrifoliae in the PEG confirmed the Beehold tube's functionality as non-sacrificial subsampling tool. Based on the pollen, the bees foraged exclusively on strawberry during the study period. The pollen data show that honey bee colonies had not foraged on strawberry prior to translocation in the greenhouse, and once in the greenhouse, forager bees visited solely strawberry flowers in the greenhouse. In the pre-sampled colony of the first cohort colonies and in the first subsampled colonies on March 18, no E. pyrifoliae bacteria were detected, showing that this bacterium was not present in the sampled colonies translocated from the apiary to the greenhouse. Furthermore, it is unlikely that the colonies carried E. pyrifoliae before translocation because known host plants (i.e. Pyrus spp.) were not blooming at the time. In the Netherlands, Pyrus pyrifolia starts blooming mid-April. We accounted for this by translocating the colonies prior to this period.

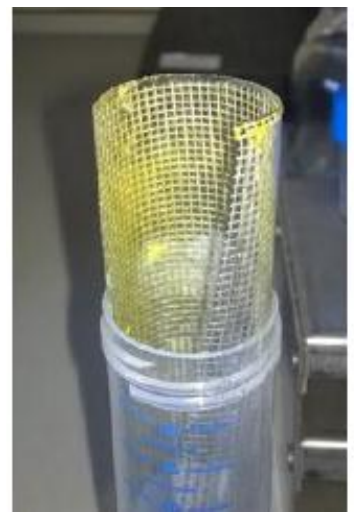

Figure 6. PEG layer with pollen

\subsection{Detection of E. pyrifoliae in the Samples of the honey bee colony and estimation of the Timing of the Influx of E. pyrifoliae into the Colony}

In the honey bee colony, E. pyrifoliae bacteria were detected from March 25 and solely on one sampling location in the greenhouse. This may be the result of separate or interacting features such as bees of this colony visited more infected flowers than the other sampled colony, foragers of the colonies in the greenhouse were not homogeneously dispersed over the flowers, little influx of E. pyrifoliae bacteria, which was diluted by in-hive exchange to a non-detectable level, and the presence of $E$. pyrifoliae started on single spots and not all flowers are diseased. The latter was certainly the case as flowers showing symptoms of the E. pyrifoliae infection were heterogeneously distributed among the greenhouse. The grower estimated a $10 \%$ infection rate of flowers on April 15. Based on the known short viability of the related bacterium E. amylovora in a honey bee colony of some days (Wael, 1988), the data suggest a constant influx of new E. pyrifoliae bacteria from March 25. The second cohort of honey bee colonies placed in the greenhouse on April 3 were first sampled 5 days later. This sampling revealed E. pyrifoliae, and demonstrates that 4 days is sufficient for E. pyrifoliae to enter the hive by distributed among its workers.

\subsection{Sacrificial and Non-sacrificial Sampling of the Honey bee Colony for Detection of E. pyrifoliae}

The results show that sacrificial subsampling of in-hive bees was more sensitive compared to the Beehold tube. E. pyrifoliae was detected on in-hive bees prior to any symptoms of an E. pyrifoliae infection. Apparently sufficient bacteria were collected by the foraging bees to be detectable on the in-hive bee cohort in the period prior to any visible symptoms in the strawberry. With the Beehold tube, E. pyrifoliae detection coincided with the first visible symptoms of plant infection. Adherence of the bacterium to the PEG appeared to be insufficient to accumulate enough E. pyrifoliae bacteria for detection at this early stage of the infection. To improve non-sacrificial subsampling for bio sampling of E. pyrifoliae prior to the appearance of the ooze droplets, 
adherence of bacteria to the PEG and the intensification of the contact between PEG and hive-entering bees should be improved. The longevity of $E$. pyrifoliae on the honey bee's exterior is not known. Assuming the same survival period of E. pyrifoliae in a honey bee colony, the detection of E. pyrifoliae on March 24 indicates that foragers collected the bacterium from March 22.

In conclusion, the integration of pollination and bio sampling of plant pathogens by a honey bee colony is possible. Both sacrificial- and non-sacrificial sampling of honey bee colonies can be applied for qualitative bio sampling of E. pyrifoliae in strawberry greenhouse cultivation during flowering. E. pyrifoliae was detected via sacrificial subsampling of in-hive bees prior to visible symptoms of the infection in the strawberry flowers. Detection of E. pyrifoliae by non-sacrificial sampling with the Beehold tube was less sensitive, and coincided with the first visible symptoms of the E. pyrifoliae infection in the flowers. Future studies with other pollinating insects like bumble bees and application of the Beehold device may extend this combination of pollination and bio sampling.

\section{Acknowledgement}

The authors acknowledge Mr. A. Vermeulen for his hospitality and for allowing us to use his strawberry greenhouse. We would also like to thank Mr. R. Schuurmans making his honey bee colonies available for this study. This study was made possible by the financial support of NVWA, OS project entitled: Epidemiological elements of a new pathogen Erwinia sp. in strawberry, related to Erwinia pyrifoliae.

\section{References}

Atanasova, I., Kabadjova, P., Bogatzevska, N., \& Moncheva, P. (2005). New host plants of Erwinia amylovora in Bulgaria. Zeitschrift für Naturforschung C, 60(11-12), 893-898. https://doi.org/10.1515/znc-2005-11-1212

Bonn, W. G., \& van der Zwet, T. (2000). Fire Blight The Disease and its Causative Agent, Erwinia amylovora (JL Vanneste ed.). CABI Pub. Wallingford, 37-53. https://doi.org/10.1079/9780851992945.0037

Bozic, J., \& Valentincic, T. (1995). Quantitative analysis of social grooming behavior of the honeybee Apis mellifera carnica. Apidologie, 26, 141-141. https://doi.org/10.1051/apido:19950207

Crailsheim, K. (1985). Distribution of haemolymph in the honeybee (Apis mellifera) in relation to season, age and temperature. Journal of Insect Physiology, 31(9), 707-713. https://doi.org/10.1016/0022-1910(85)90051-4

Dafni, A., Hesse, M., \& Pacini, E. (Eds.). (2012). Pollen and pollination. Springer Science \& Business Media.

Degrandi-Hoffman. G., Hoopingarner, R., \& Baker, K. (1984). Pollen transfer in pear orchards: tree-to tree or bee-to-bee? Bee World, 65, 126-133. https://doi.org/10.1080/0005772X.1984.11098791

Degrandi-Hoffman, G., Hoopingarner, R., \& Klomparens. (1986). Influence of honeybee (Hymenoptera: Apidae)in-hive pollen transfer on cross pollination and fruit set in apple. Environmental Entomology, 15(3), 723-725. https://doi.org/10.1093/ee/15.3.723

Delaplane, K. S., Steen, J. J. M. van der \& Guzman-Novoa, E. (2013). Standard methods for estimating strength parameters of Apis mellifera colonies. Journal of Apicultural Research, 52(1), 1-12.

https://doi.org/10.3896/IBRA/1.52.1.03

Eckert, C. D., Winston, M. L., \& Ydenberg, R. C. (1994). The relationship between population size, amount of brood, and individual foraging behaviour in the honeybee, Apis mellifera L. Oecologia, 97(2), 248-255. https://doi.org/10.1007/BF00323157

Free, J. B., \& Williams, I. H. (1972). The transport of pollen on the body hairs of honeybees (Apis mellifera L.) and bumblebees (Bombus spp. L.) Journal of Applied Ecology, 609-615. https://doi.org/10.2307/2402458

Halbwirth, H., Gosch, C., Stich, K., Persen, U., Marco-Noales, E., Lòpez, M. M., ... Petrutis, K. (2014). Endbericht Forschungsprojekt Nr. 100867 (Phytfire): ERA-NET EUPHRESCO II: Methoden zum Nachweis von Erwinia amylovora zur phytosanitären Diagnose, raschen vor ort-Analyse und epidemiologischen Erfassung, Work Package 4: Vektor Monitoring. www.dafne.at

Hodges, D. (1974). Pollen loads of the honeybee: a guide to their identification by colour and form. London, Bee Research Association.

Kennedy, B. W., \& King, T. H. (1962). Studies on epidemiology of bacterial angular leafspot on strawberry. Plant Disease Reporter, 46, 360-3.

Kevan, P. G., Kapongo, J., Al-mazra'awi, M., \& Shipp, L. (2008). Honey bees, bumble bees and biocontrol. 
Bee pollination in agriculture ecosystems. Oxford University Press, New York.

Kovach, J., Petzoldt, R., Gary, E., \& Harman, G. E. (2000). Use of honey bees and bumble bees to disseminate Trichoderma harzianum 1295-22 to strawberries for Botrytis control. Biological Control, 18(3), $235-242$. https://doi:10.1006/bcon.2000.0839

Lukoschus, F. S. (1957). Quantitative Untersuchungen über den Pollentransport im Haarkleid der Honigbiene. Zeitschrift für Bienenforschung, 4, 1-19.

Nixon, H. L., \& Ribbands, C. R. (1952). Food transmission within the honeybee community. Proceedings of the Royal Society of London. Series B-Biological Science, 140(898), 43-50. https://doi.org/10.1098/rspb.1952.0042

Paalhaar, J., Boot, W. J., Steen, J. J. M. van der, \& Calis, J. N. M. (2008). In -hive pollen transfer between bees enhances cross-pollination of plants. In Proc. Neth. Entomol. Soc. Meeting, 19, 53-58.

Pernal, S. F., \& Currie, R. W. (2001). The influence of pollen quality on foraging behavior in honeybees (Apis mellifera L.). Behavioral Ecology and Sociobiology, 51(1), 53-68. https://doi.org/10.1007/s002650100412

Porrini, C., Sabatini, A. G., Carpana, E., Alexandrova, M., Medrzycki, P., Bortolotti, L., ... Girotti, S. (2002). Studi sul ruole delle api nella disseminazione del batteria Erwinia amylovora e come bioindicatori della presenza de fitopatogene nell'ambiente. In Proceedings of the XIX Italian national Congress of Entomology (pp1309-1318).

Wadl, P. A., Skinner, J. A., Dunlap, J. R. Reed, S. M., Rinehart, T. A., Pantalone, V. R., \& Trigiano, R. N. (2009) Honeybee-mediated controlled pollination in Cornus florida and C. kousa intra- and interspecific crosses. Horticultural Science, 44(6), 1527-1533

Wael, de L. (1988). De honingbij als mogelijke vector van Erwinia amylovora (Burr). Proefschrift Faculteit van de Landbouwwetenschappen Gent.

Wenneker, M., \& Bergsma-Vlami, M. (2015). Erwinia pyrifoliae, a new pathogen on strawberry in the Netherlands. Journal of Berry Research, 5(1), 17-22.

Wensing A., Gernold M., \& Geider K. (2011). Detection of Erwinia species from the apple and pear flora by mass spectroscopy of whole cells and with novel PCR primers. Journal of Applied Microbiology, 112, 147-158. https://doi.org/10.1111/j.1365-2672.2011.05165

\section{Copyrights}

Copyright for this article is retained by the author(s), with first publication rights granted to the journal.

This is an open-access article distributed under the terms and conditions of the Creative Commons Attribution license (http://creativecommons.org/licenses/by/3.0/). 